Article

\title{
In Situ Preparation of Amphibious ZnO Quantum Dots with Blue Fluorescence Based on Hyperbranched Polymers and their Application in Bio-Imaging
}

\author{
Gaiying Lei ${ }^{1, \dagger}$, Shu Yang ${ }^{2,3, \dagger}$, Ranran Cao ${ }^{2,3, \dagger}$, Peng Zhou ${ }^{2,3}$, Han Peng ${ }^{2,3}$, Rui Peng ${ }^{2,3}$, \\ Xiaoming Zhang ${ }^{2,3}$, Yujiao Yang ${ }^{2,3}$, Yueyang $\mathrm{Li}^{2,3}$, Mengyue Wang ${ }^{2,3}$, Yaru He ${ }^{2,3}$, \\ Linzhu Zhou ${ }^{4}$, Jimin Du ${ }^{2,3}$, Weimin Du ${ }^{2,3}$, Yunfeng Shi ${ }^{2,3, *(D)}$ and Hankui $\mathbf{W u}^{2,3, *}$ \\ 1 School of Chemistry and Chemical Engineering, Henan Normal University, Xinxiang 453007, China; \\ lgying1006@163.com \\ 2 School of Chemistry and Chemical Engineering, Anyang Normal University, Anyang 455000, China; \\ Y15736967669@163.com (S.Y.); c15864418126@163.com (R.C.); z181001066@163.com (P.Z.); \\ ph18337278759@163.com (H.P.); pr15896849973@163.com (R.P.); 18337278676@163.com (X.Z.); \\ y15042611565@163.com (Y.Y.); 18637818665@163.com (Y.L.); myw0618@163.com (M.W.); \\ heyaru1999@163.com (Y.H.); djm@aynu.edu.cn (J.D.); dwmchem@163.com (W.D.) \\ 3 Henan Province Key Laboratory of New Optoelectronic Functional Materials, Anyang Normal University, \\ Anyang 455000, China \\ 4 School of Chemistry and Chemical Engineering, Shanghai Jiao Tong University, 800 Dongchuan Road, \\ Shanghai 200240, China; linzhu.zhou@hotmail.com \\ * Correspondence: shiyunfeng2009@gmail.com (Y.S.); hkwu@aynu.edu.cn (H.W.) \\ + These authors are joint first authors.
}

Received: 24 November 2019; Accepted: 1 January 2020; Published: 6 January 2020

Abstract: A new strategy for preparing amphibious $\mathrm{ZnO}$ quantum dots (QDs) with blue fluorescence within hyper-branched poly(ethylenimine)s (HPEI) was proposed in this paper. By changing $\left[\mathrm{Zn}^{2+}\right] /\left[\mathrm{OH}^{-}\right]$molar ratio and heating time, $\mathrm{ZnO}$ QDs with a quantum yields (QY) of $30 \%$ in ethanol were obtained. Benefiting from the amphibious property of HPEI, the $\mathrm{ZnO} / \mathrm{HPEI}$ nanocomposites in ethanol could be dissolved in chloroform and water, acquiring a QY of $53 \%$, chloroform and $11 \%$ in water. By this strategy, the $\mathrm{ZnO} / \mathrm{HPEI}$ nano-composites could be applied in not only in optoelectronics, but also biomedical fields (such as bio-imaging and gene transfection). The bio-imaging application of water-soluble $\mathrm{ZnO} / \mathrm{HPEI}$ nanocomposites was investigated and it was found that they could easily be endocytosed by the COS-7 cells, without transfection reagent, and they exhibited excellent biological imaging behavior.

Keywords: hyperbranched polymers; amphibious $\mathrm{ZnO}$ quantum dots; blue fluorescence; bio-imaging

\section{Introduction}

Semiconductor quantum dots (QDs) show unique size- and shape-dependent optical and electronic properties [1-7]. They are of great interest in various applications, such as optoelectronics $[8,9]$, biophotonics [10-15], and nanomedicine [14-16]. Among these QDs, cadmium series QDs (such as CdSe [17], CdSe/CdS [18]) and zinc series QDs (such as ZnSe [19], ZnO [20-22]) often have excellent fluorescence. However, cadmium series QDs are actually toxic under certain conditions and free $\mathrm{Cd}^{2+}$ ions can be liberated from QDs, resulting in the cytotoxicity of QDs [23]. While, ZnO QDs are a cheap nanomaterial with non-toxic properties, they have great application in bio-medical fields, such as bio-imaging and drug release.

$\mathrm{ZnO}$ QDs are often prepared by the facile sol-gel approach [20,24-26] Zinc salts (such as $\mathrm{Zn}(\mathrm{OAc})_{2}, \mathrm{Zn}\left(\mathrm{NO}_{3}\right)_{2}$, zinc methacrylate), and alkali (such as $\mathrm{LiOH}$, diethanolamine) are used as 
precursors. By varying the $\left[\mathrm{Zn}^{2+}\right] /\left[\mathrm{OH}^{-}\right]$molar ratio, the size tunability of defect rich $\mathrm{ZnO}$ QDs was achieved, resulting in size tunable visible emission of $\mathrm{ZnO}$ QDs, with the quantum yield as high as $76 \%$ [20,24]. Ionic liquid [27] and polymers [28-30], such as poly (ethylene glycol) methyl ether (PEGME) have also been used to prepare size-controlled ZnO QDs with quantum yield as high as $45 \%$. Xiong et al. developed a two-step polymerization method, where they combined the polymerization or copolymerization of monomers (such as poly (ethylene glycol) methyl ether methacrylate (PEGMEMA) [31], methacrylic acid (MAA) [32], methyl methacrylate (MMA) [32], and methacrylamide [33]) with the in situ preparation of ZnO QDs to gain core-shell-structured ZnO@polymer QDs.

Until now, the polymers or monomers, used for $\mathrm{ZnO}$ quantum dot synthesis, always have carboxyl groups, ester groups, or amide groups. Therefore, the resulting $\mathrm{ZnO} /$ polymer nanocomposites cannot be applied in gene transfection because polymers with such groups cannot condense DNA well or at all. Hyperbranched poly(ethylenimine)s (HPEI), with a three-dimensional structure and abundant amine groups, have been regarded as one of the most promising non-viral gene vectors due to the proton sponge effect [34-37]. If HPEI are used as nanoreactors to synthesize fluorescent ZnO QDs, the advantages of HPEI (such as amphibious property, gene transfection and drug delivery capability) and $\mathrm{ZnO}$ QDs (such as fluorescence) could be integrated together, endowing the $\mathrm{ZnO} / \mathrm{HPEI}$ nanocomposites with fluorescence, gene transfection, and amphibious properties. Herein, HPEI were applied as nanoreactors to synthesize amphibious $\mathrm{ZnO}$ QDs with blue fluorescence. The effect of $\left[\mathrm{Zn}^{2+}\right] /\left[\mathrm{OH}^{-}\right]$ molar ratio and heating time on the fluorescence performance of prepared $\mathrm{ZnO}$ QDs was investigated. The amphibious property and fluorescence of the resulting $\mathrm{ZnO} / \mathrm{HPEI}$ nanocomposites in different solvents were also followed. For the water-soluble $\mathrm{ZnO} / \mathrm{HPEI}$ nanocomposites, they could easily be endocytosed by the COS-7 cells without other transfection reagent benefiting from the gene transfection property of HPEI and exhibited excellent biological imaging behavior.

\section{Experimental Section}

\subsection{Materials}

Hyperbranched polyethylenimines (HPEI) (Degree of Branching (DB) $=60 \%, M n=1 \times 10^{4}$, PDI $=2.5)$, zinc acetate $\left(\mathrm{Zn}(\mathrm{AC})_{2}, 99.99 \%\right)$ and sodium hydroxide $(\mathrm{NaOH}, 99.99 \%)$ were bought from Sigma-Aldrich (Saint Louis, MO, USA). Ethanol and chloroform were purchased from Sinopharm Chemical Reagent Co. Ltd. (Shanghai, China). The ultrapure water with $18.2 \mathrm{M} \Omega \cdot \mathrm{cm}$ was used in all experiments.

\subsection{Synthesis and Bio-Imaging Application}

\subsubsection{Synthesis of HPEI/Zn ${ }^{2+}$}

A totally of $384.0 \mathrm{mg}$ of HPEI was dissolved by $30 \mathrm{~mL}$ of ethanol in a $250 \mathrm{~mL}$ conical flask. Then, the solution $13.0 \mathrm{mg}$ of $\mathrm{Zn}(\mathbf{O A C})_{2}$ in $10 \mathrm{~mL}$ of ethanol was added. The mixture was vigorously stirred for 2 days.

2.2.2. Synthesis of Amphibious ZnO QDs with Blue Fluorescence Based on HPEI Hyperbranched Polymers

Typically, $10 \mathrm{~mL}$ of HPEI/ $/ \mathrm{Zn}^{2+}$ was deoxygenated and stirred in two-neck flask. Reflux was carried out for $2 \mathrm{~h}$ with oil bath heating at $100{ }^{\circ} \mathrm{C}$ under ordinary pressure. The heating temperature was then cooled down to $80^{\circ} \mathrm{C}$ and $1.4 \mathrm{mg}$ of $\mathrm{NaOH}\left(\left[\mathrm{Zn}^{2+}\right] /\left[\mathrm{OH}^{-}\right]=1: 2\right)$ in $4 \mathrm{~mL}$ ethanol and $1 \mathrm{~mL}$ ultrapure water was quickly injected into the reaction flask. Test samples were taken out from the reaction flask at 2, 4, 6, 8, and $10 \mathrm{~h}$, respectively. The sample collected at $10 \mathrm{~h}$ was abbreviated as $\mathrm{ZnO}_{1: 2} / \mathrm{HPEI}-10$ nanocomposites. A similar procedure was also applied for other $\mathrm{ZnO}$ quantum dot synthesis under different $\left[\mathrm{Zn}^{2+}\right] /\left[\mathrm{OH}^{-}\right]$molar ratios such as $1: 1$ and 1:4. 


\subsubsection{Bio-Imaging Application of $\mathrm{ZnO} / \mathrm{HPEI}$ Nanocomposites with Blue Fluorescence}

The original ethanol solution of $\mathrm{ZnO} / \mathrm{HPEI}$ nanocomposites were firstly concentrated and then dialyzed by dialysis bag with molecular weight cut off (MWCO) of $1 \mathrm{k}$ Da against distilled water to obtain an aqueous solution of $\mathrm{ZnO} / \mathrm{HPEI}$ nanocomposites. The original culture medium of COS-7 cells was replaced by phosphate buffer solution (PBS) solution of $\mathrm{ZnO} / \mathrm{HPEI}$ nanocomposites. After culturing for $6 \mathrm{~h}$, the cell imaging of $\mathrm{ZnO} / \mathrm{HPEI}$ nanocomposites were characterized by fluorescence microscopy (Olympus Optical Co., Tokyo, Japan).

\subsection{Measurements}

Transmission electron microscopy (TEM) and elemental characterization were performed on a FEI Tecnai F20 microscope (Thermo Fisher Scientific, Waltham, MA, USA), with an energy-dispersive X-ray spectrometer (EDS) (Thermo Fisher Scientific, Waltham, MA, USA), at an accelerating voltage of $200 \mathrm{kV}$. The ethanol solution of $\mathrm{ZnO} / \mathrm{HPEI}$ nanocomposites was filtered by $220 \mathrm{~nm}$ polyethersulfone filter and sonicated for $10 \mathrm{~s}$ immediately before TEM sample preparation. TEM samples were made by adding $10 \mu \mathrm{L}$ ethanol solution of $\mathrm{ZnO} / \mathrm{HPEI}$ nanocomposites to a copper grid coated with ultrathin carbon film. UV-Vis spectra were characterized on a UV-1780 spectrophotometer with a $1 \mathrm{~cm}$ quartz spectrophotometer cell. For the quantum yield (QY) measurement, the solutions of ZnO/HPEI nanocomposites were commonly diluted with the corresponding solvents to make the absorbance at an excitation wavelength $(360 \mathrm{~nm})$ in the range of 0.03 to 0.1 . Photoluminescence (PL) spectra were investigated by using a Cary Eclipse spectrometer (Agilent, Santa Clara, CA, USA) with an excitation wavelength of $360 \mathrm{~nm}$. Dynamic light scattering (DLS) data were collected on a Zetasizer Nano-ZS (Malvern Instruments, Malvern, United Kingdom). Photographs were taken with a SAMSUNG WB150F digital camera (Samsung, Seoul, South Korea). TGA weight loss curves were acquired by using Netzsch STA-449F3 (Netzsch, Selb, Germany) under nitrogen at a heating rate of $20^{\circ} \mathrm{C} / \mathrm{min}$ from 30 to $800^{\circ} \mathrm{C}$.

\section{Results and Discussion}

HPEI have a large number of primary, secondary, and tertiary amines. $\mathrm{Zn}^{2+}$ ions were firstly complexed with the amine groups of HPEI, and then reacted with alkali, which was supplied by HPEI or addition. After refluxing for several hours, fluorescent $\mathrm{ZnO}$ QDs with blue emission were obtained based on HPEI, as shown in Scheme 1a-c. After dialysis, the ZnO/HPEI nanocomposites with blue emission were applied on bio-imaging, as shown in Scheme $1 \mathrm{~d}$.

The UV-Vis and photoluminescence spectra of ZnO QDs synthesized under different $\left[\mathrm{Zn}^{2+}\right] /\left[\mathrm{OH}^{-}\right]$ molar ratios and various heating times are shown in Figure 1. For the $\mathrm{ZnO}$ QDs prepared under a $\left[\mathrm{Zn}^{2+}\right] /\left[\mathrm{OH}^{-}\right]$molar ratio of 1:2, the absorption peaks locate at approximately 325 and $383 \mathrm{~nm}$. The absorption peaks have no significant change under various heating time, as shown in Figure $1 \mathrm{a}$. The corresponding emission peaks of $\mathrm{ZnO}$ QDs, shown in Figure 1b, locate at 408-411 nm under different heating time. The inset photo shows the $\mathrm{ZnO}$ QDs emit blue light under UV light.

For the $\mathrm{ZnO}$ QDs prepared under $\left[\mathrm{Zn}^{2+}\right] /\left[\mathrm{OH}^{-}\right]$molar ratio of $1: 1$ and $1: 4$, the UV-Vis and PL spectra of $\mathrm{ZnO}$ QDs have no remarkable variation compared with those of $\mathrm{ZnO}$ QDs made under a $\left[\mathrm{Zn}^{2+}\right] /\left[\mathrm{OH}^{-}\right]$molar ratio of $1: 2$. This indicates that the heating time and molar ratios of $\left[\mathrm{Zn}^{2+}\right] /\left[\mathrm{OH}^{-}\right]$ have no significant effect on the optical properties of $\mathrm{ZnO}$ QDs. For the common sol-gel approach used for ZnO QD synthesis [20,24-26], zinc salts and alkali were used to prepare size-controlled ZnO QDs without other stabilizers, and the hydroxyl ions and their counter ions actually as a capping layer around the QDs, thus, the size-tunability of $\mathrm{ZnO}$ QDs could be realized by $\left[\mathrm{Zn}^{2+}\right] /\left[\mathrm{OH}^{-}\right]$molar ratios. Here, HPEI, with a three-dimensional architecture and plenty of amines, were used to segregate, stabilize and control the size of $\mathrm{ZnO}$ QDs. The size-tunability of $\mathrm{ZnO}$ QDs might be tuned by adjusting the molar ratio of $\left[\mathrm{Zn}^{2+}\right] /[\mathrm{HPEI}]$, as reported in our previous work for $\mathrm{Fe}_{3} \mathrm{O}_{4}$ nanocrystal synthesis [37]. 
The hydroxyl ions and their counter ions cannot control the size ZnO QDs anymore, but they could still adsorb on the surface of $\mathrm{ZnO}$ QDs and influence the emission property of ZnO QDs.

The quantum yields (QY) of ZnO QDs were measured according to the method described in reference [38]. Cumarin 1 was chosen as a reference standard $(\mathrm{QY}=0.73)$. The $\mathrm{QY}$ of $\mathrm{ZnO}$ QDs synthesized under different $\left[\mathrm{Zn}^{2+}\right] /\left[\mathrm{OH}^{-}\right]$molar ratios were monitored during the heating process and the results show that the QY of $\mathrm{ZnO}$ QDs, prepared under different $\left[\mathrm{Zn}^{2+}\right] /\left[\mathrm{OH}^{-}\right]$molar ratios, could all reach 30\%, as shown in Figure 2. The QY of $\mathrm{ZnO}$ QDs prepared under a $\left[\mathrm{Zn}^{2+}\right] /\left[\mathrm{OH}^{-}\right]$molar ratio of 1:2 and various heating times showed better results compared with other conditions, indicating the hydroxyl ions and their counter ions virtually influence the optical properties of $\mathrm{ZnO}$ QDs, even in the presence of HPEI.<smiles>NCCNCCN(CCN)CCN(CCN(CCN)CCN)CCN(CCN(CCN)CCN)CCN(CCNCCN)CCN(CCN)CCN</smiles>

(HPEI)

(d)

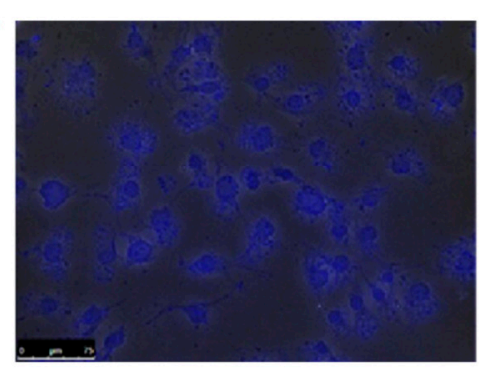

(Cell imaging) (b)

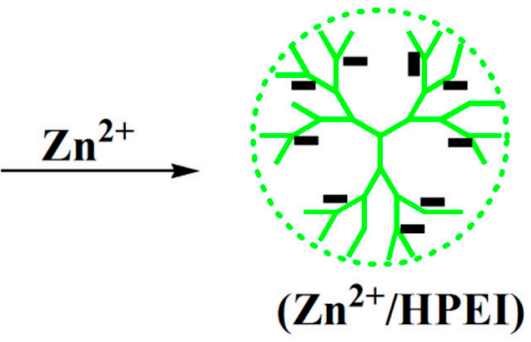

(c)

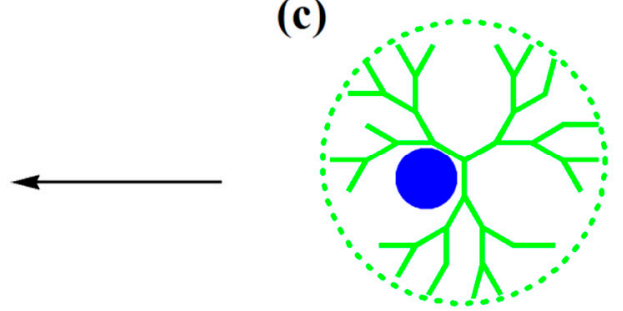

(ZnO/HPEI nanocomposites)

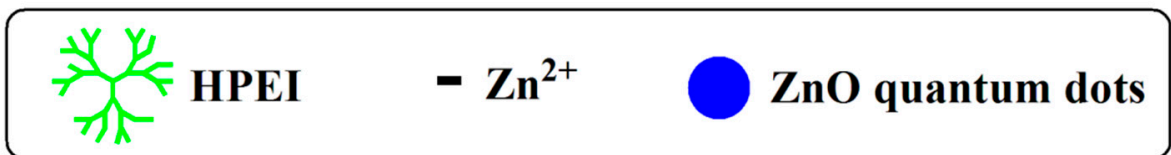

Scheme 1. Illustration for the synthesis of fluorescent and amphibious $\mathrm{ZnO}$ quantum dots (QDs) based on hyperbranched poly(ethylenimine)s (HPEI) $(\mathbf{a}-\mathbf{c})$ and their application in cell imaging $(\mathbf{d})$. 

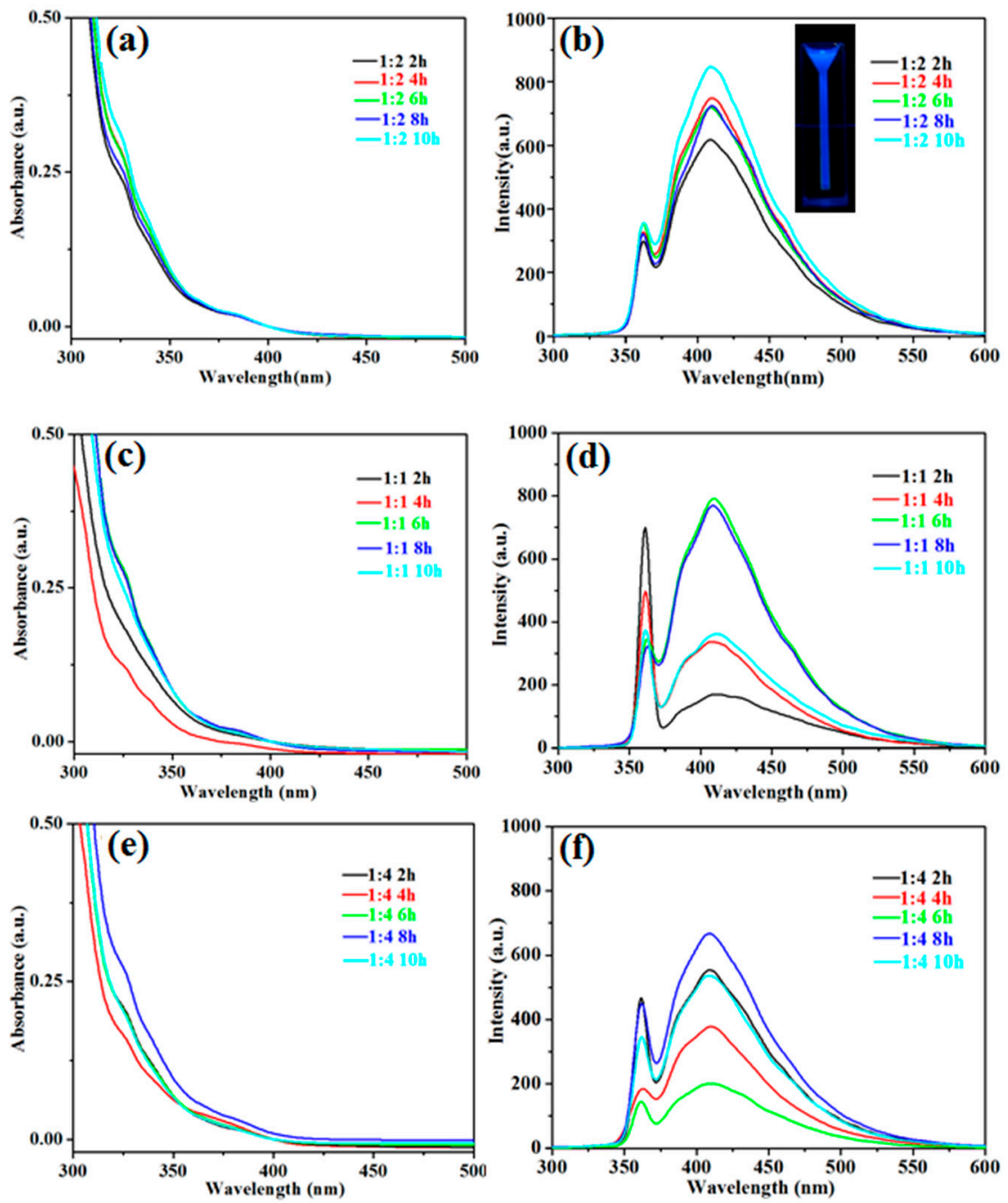

Figure 1. UV-Vis $(\mathbf{a}, \mathbf{c}, \mathbf{e})$ and PL $(\mathbf{b}, \mathbf{d}, \mathbf{f})$ spectra of $\mathrm{ZnO}$ QDs synthesized under different $\left[\mathrm{Zn}^{2+}\right] /\left[\mathrm{OH}^{-}\right]$ molar ratios ((a,b) 1:2, (c,d) 1:1, (e,f) 1:4) and various heating times (2, 4, 6, 8 and $10 \mathrm{~h})$. Photoluminescence (PL) spectra were recorded with excitation at $360 \mathrm{~nm}$. Inset photo of ZnO QDs was taken under UV light (365 nm).

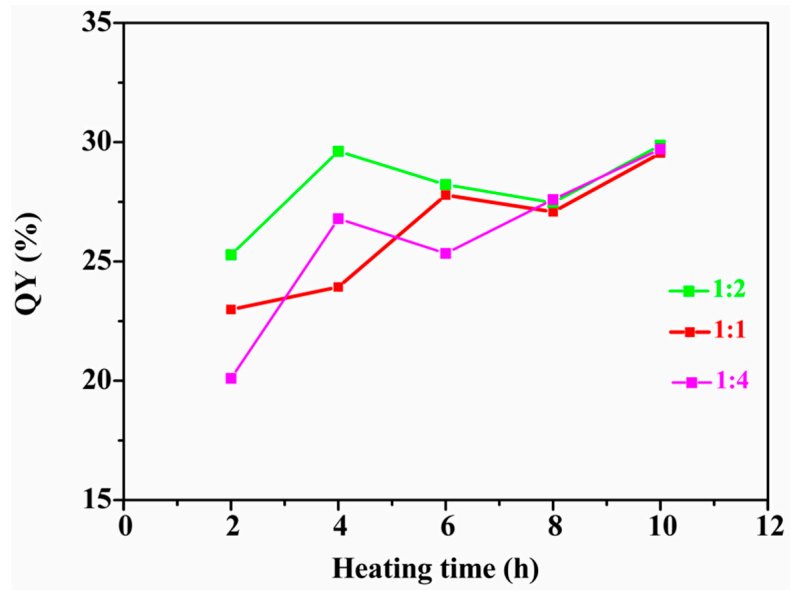

Figure 2. The quantum yields (QY) of $\mathrm{ZnO}$ QDs synthesized under different $\left[\mathrm{Zn}^{2+}\right] /\left[\mathrm{OH}^{-}\right]$molar ratios and heating times. 
Transmission electronic microscopy (TEM) was used to characterize the morphology and size distribution of $\mathrm{ZnO}_{1: 2} / \mathrm{HPEI}-10$ nanocomposites, which were synthesized with $\left[\mathrm{Zn}^{2+}\right] /\left[\mathrm{OH}^{-}\right]$molar ratio of 1:2 and $10 \mathrm{~h}$ heating, as shown in Figure 3. It can be seen the $\mathrm{ZnO}$ QDs are relatively uniform and monodisperse. This is because HPEI could segregate $\mathrm{ZnO} Q D$ s and prevent their aggregation. The $\mathrm{ZnO}$ QDs have a mean diameter of $3.0 \mathrm{~nm}$ by measuring hundreds of nanoparticles. The corresponding EDS spectrum, shown in Figure $3 b$, displays the signals of $Z n$ and O elements, confirming the existence of $\mathrm{ZnO}$ QDs.
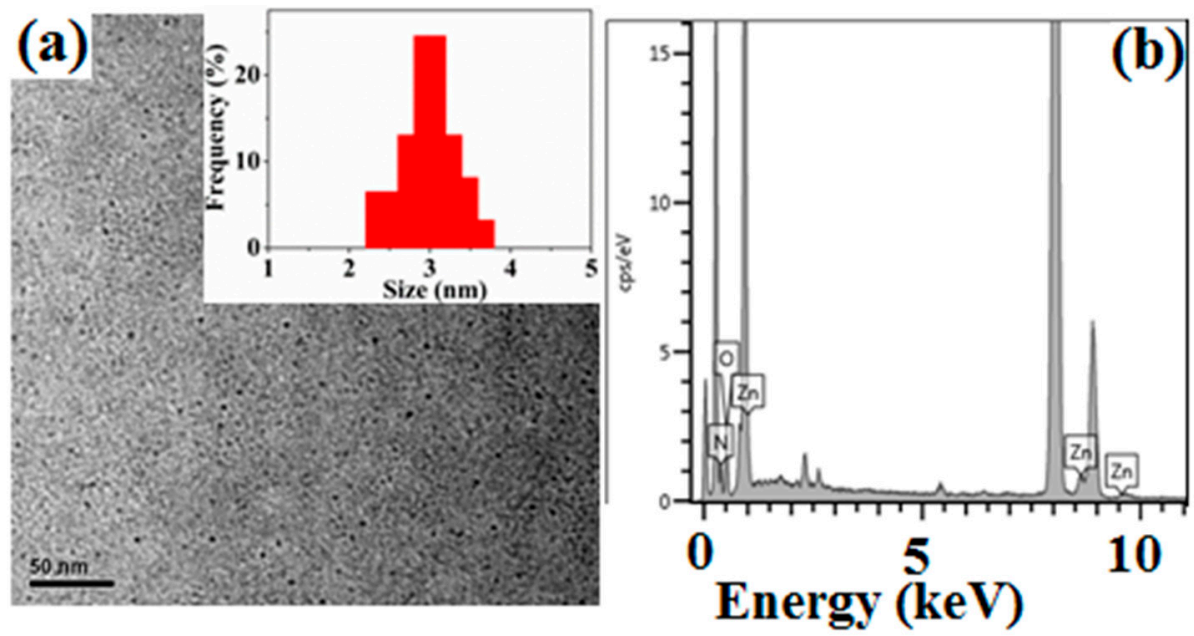

Figure 3. Transmission electron microscopy (TEM) image (a) and energy-dispersive $X$-ray spectrometer (EDS) spectrum (b) of $\mathrm{ZnO}$ QDs synthesized under a $\left[\mathrm{Zn}^{2+}\right] /\left[\mathrm{OH}^{-}\right]$molar ratio of 1:2 and $10 \mathrm{~h}$ heating. The scale bar is $50 \mathrm{~nm}$. The inset shows the size distribution of $\mathrm{ZnO}$ QDs.

Figure 4 shows the size distribution of neat HPEI and $\mathrm{ZnO}_{1: 2} / \mathrm{HPEI}-10$ nanocomposites, measured by DLS. The hydrodynamic diameter of neat HPEI is $3.6 \mathrm{~nm}$, while the $\mathrm{ZnO}_{1: 2} / \mathrm{HPEI}-10$ nanocomposites have a diameter of $4.9 \mathrm{~nm}$. According to TEM data and the hydrodynamic diameter change of HPEI before, and after, quantum dot (QD) synthesis, the ZnO QDs should be encapsulated into the interior cavities of HPEI and one ZnO QD is complexed with each HPEI in average.

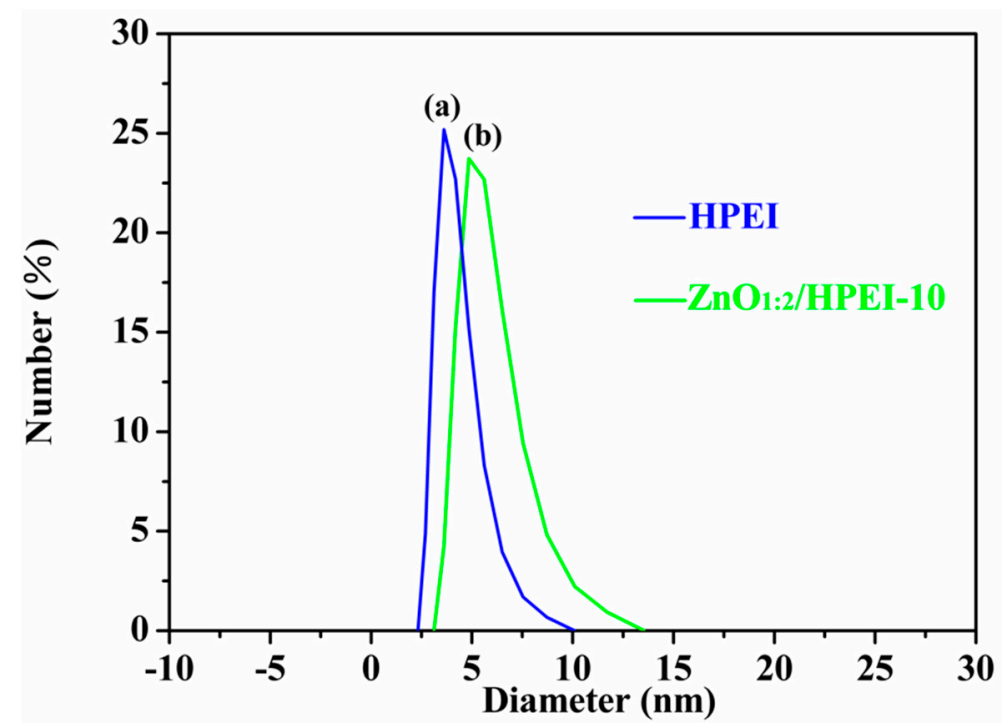

Figure 4. Size distribution of (a) neat HPEI and (b) $\mathrm{ZnO}_{1: 2} / \mathrm{HPEI}-10$ nanocomposites, measured by DLS.

Figure 5 shows a comparison of FT-IR spectra between 4000 and $500 \mathrm{~cm}^{-1}$ of neat HPEI and $\mathrm{ZnO}_{1: 2} / \mathrm{HPEI}-10$ nanocomposites. The $\mathrm{N}-\mathrm{H}$ stretching vibration of primary and secondary amine 
groups in HPEI locate at $3286 \mathrm{~cm}^{-1}$ in Figure $5 \mathrm{a}$, and it red shift to $3429 \mathrm{~cm}^{-1}$ in Figure $5 \mathrm{~b}$ for the $\mathrm{ZnO}_{1: 2} / \mathrm{HPEI}-10$ nanocomposites. The bands at 2917 (or 2921) and 2813 (or 2850) $\mathrm{cm}^{-1}$ in all curves correspond to asymmetric $-\mathrm{CH}_{2}-$ stretching vibration, and symmetric $-\mathrm{CH}_{2}-$ stretching vibration, respectively. The bending vibrations of primary amines and secondary amines, in HPEI in Figure 5a, appear at 1669 , and $1589 \mathrm{~cm}^{-1}$, respectively. While, the bending vibrations of primary amines and secondary amines in $\mathrm{ZnO}_{1: 2} / \mathrm{HPEI}-10$ nanocomposites shift to 1631 , and $1604 \mathrm{~cm}^{-1}$, respectively. These frequency changes in FT-IR can be attributed to the complexation interactions between amines of HPEI and $\mathrm{ZnO}$ QDs.

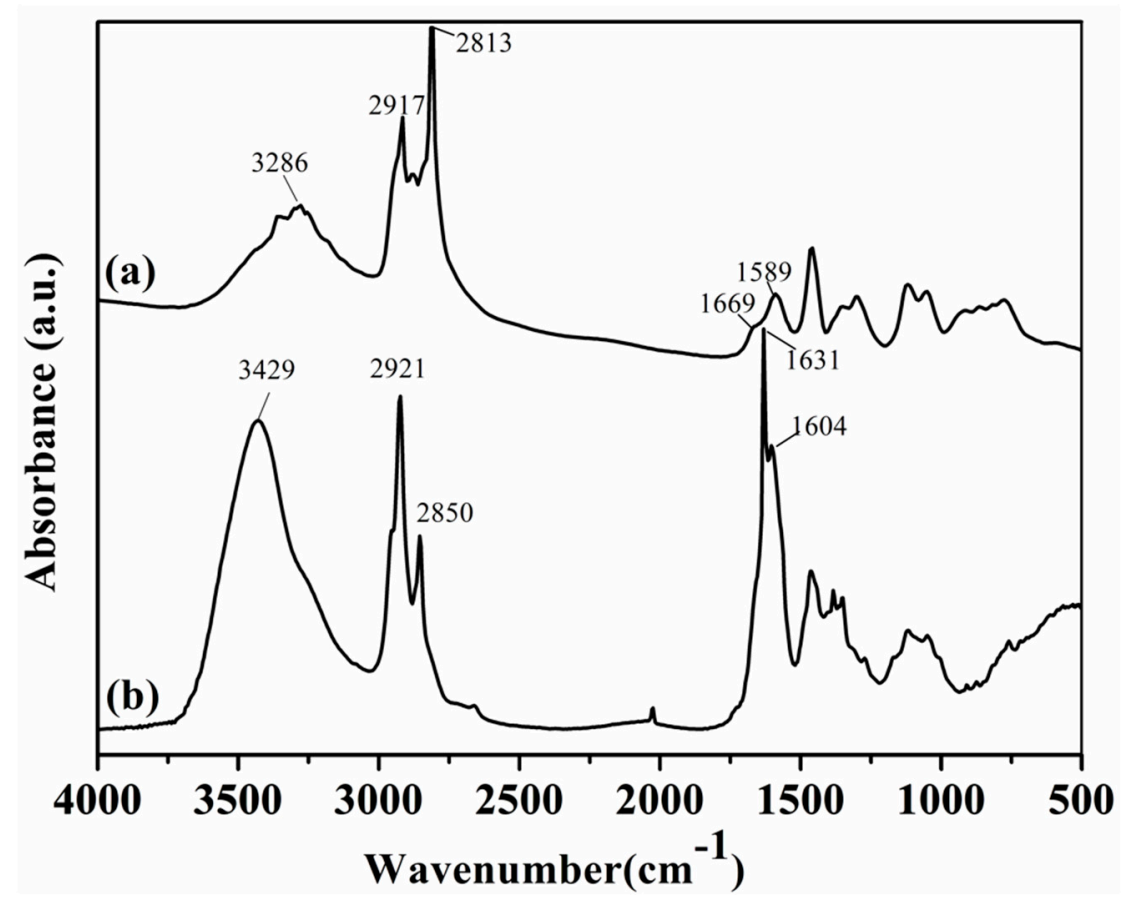

Figure 5. FT-IR spectra of (a) neat HPEI and (b) $\mathrm{ZnO}_{1: 2} / \mathrm{HPEI}-10$ nanocomposites.

The composition of $\mathrm{ZnO}_{1: 2} / \mathrm{HPEI}-10$ nanocomposites was measured by thermogravimetric analysis (TGA), as shown in Figure 6. The decomposition temperature range of neat HPEI was $295-420{ }^{\circ} \mathrm{C}$, which can be seen in Figure 6a. At $420{ }^{\circ} \mathrm{C}$, the weight loss of HPEI is $100 \mathrm{wt} \%$, indicating that HPEI have completely decomposed and volatilized. For the TGA of $\mathrm{ZnO}_{1: 2} / \mathrm{HPEI}-10$ nanocomposites, shown in Figure $6 b$, there is a certain amount of weightlessness of absorbed physics and chemistry water in the temperature range of $100-200{ }^{\circ} \mathrm{C}$. Figure $6 \mathrm{~b}$ also shows a large weight loss from 326 to $420{ }^{\circ} \mathrm{C}$, which can be assigned to the decomposition of HPEI. After $420^{\circ} \mathrm{C}$, the weight loss is unchanged and the remained mass content, assigned to $\mathrm{ZnO}$ QDs, is about 3.2\%. The content of $\mathrm{ZnO}$ QDs could be adjusted by changing the amount of $\mathrm{Zn}(\mathrm{OAc})_{2}$ and $\mathrm{NaOH}$ during $\mathrm{ZnO}$ QD synthesis. We have increased the amount of $\mathrm{Zn}(\mathrm{OAc})_{2}$ and $\mathrm{NaOH}$ to $196.6 \mathrm{mg}(1.075 \mathrm{mmol})$, and $85.7 \mathrm{mg}(2.150 \mathrm{mmol})$, respectively. While, the amount of HPEI ( $384 \mathrm{mg}, 0.0154 \mathrm{mmol})$ is unchanged. The content of $\mathrm{ZnO}$ QDs could be increased to more than $30 \%$ under such synthesis condition.

Benefiting from the excellent solubility of HPEI in many solvents, such as ethanol, chloroform, water, dimethylsulfoxide (DMSO), N-methylformamide (NMF), the $\mathrm{ZnO}_{1: 2} / \mathrm{HPEI}-10$ nanocomposites should also be soluble in these solvents. Here, the original $\mathrm{ZnO}_{1: 2} / \mathrm{HPEI}-10$ ethanol solution was dried under vacuum, and then dissolved in ethanol and chloroform with a concentration of $3 \mathrm{mg} / \mathrm{mL}$, respectively. The original $\mathrm{ZnO}_{1: 2} / \mathrm{HPEI}-10$ ethanol solution was also dialyzed by dialysis bag with molecular weight cut off (MWCO) of $1 \mathrm{k}$ Da against distilled water to get water-soluble $\mathrm{ZnO}_{1: 2} / \mathrm{HPEI}-10$ nanocomposites. Figure 7 shows a comparison of UV-Vis and PL spectra of $\mathrm{ZnO}_{1: 2} / \mathrm{HPEI}-10$ nanocomposites in ethanol, chloroform, and water, respectively. The aqueous 
$\mathrm{ZnO}_{1: 2} / \mathrm{HPEI}-10$ nanocomposites have an obvious absorption peak at $365 \mathrm{~nm}$, which is distinct from $\mathrm{ZnO}_{1: 2} / \mathrm{HPEI}-10$ nanocomposites in ethanol and chloroform phase, due to dialysis and solvent polarity differences. The corresponding emission peak has a red shift from 408 to $423 \mathrm{~nm}$, compared with that of $\mathrm{ZnO}_{1: 2} / \mathrm{HPEI}-10$ nanocomposites in an ethanol and chloroform phase. For the fluorescence property, the QY of $\mathrm{ZnO}_{1: 2} / \mathrm{HPEI}-10$ nanocomposites in ethanol, chloroform, and water is $30 \%, 53 \%$, and $11 \%$, respectively.

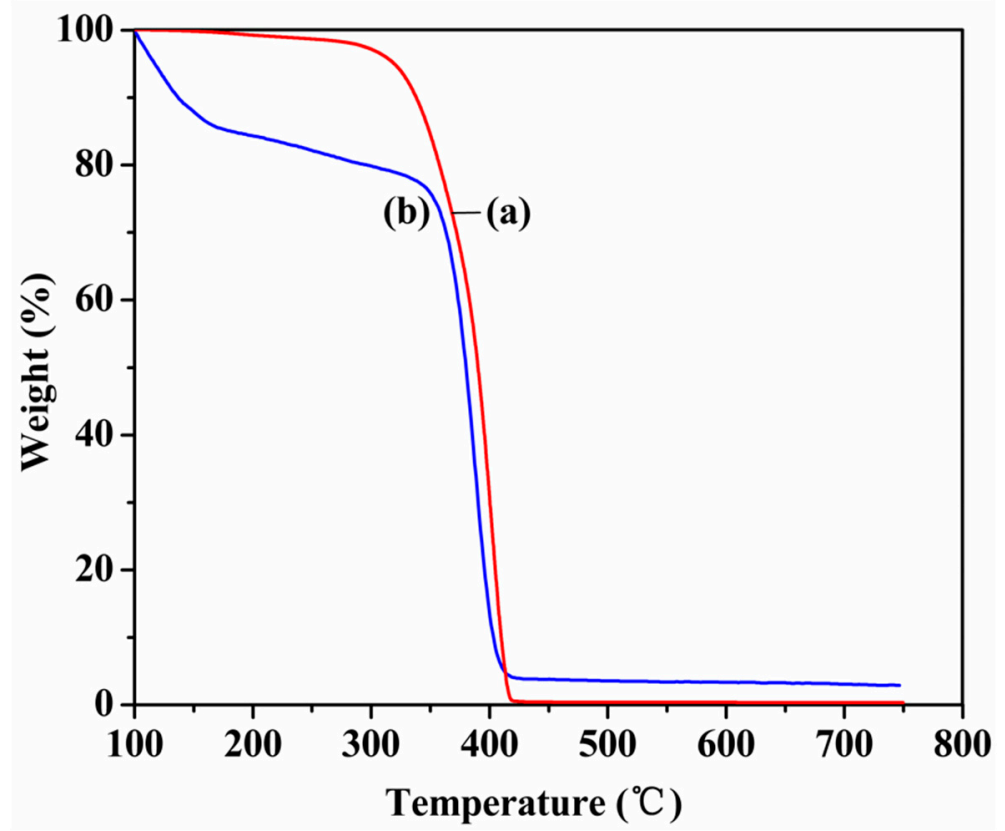

Figure 6. TGA weight loss curves of (a) neat HPEI and (b) $\mathrm{ZnO}_{1: 2} / \mathrm{HPEI}-10$ nanocomposites. The heating rate was $20^{\circ} \mathrm{C} / \mathrm{min}$ under $\mathrm{N}_{2}$ atmosphere.
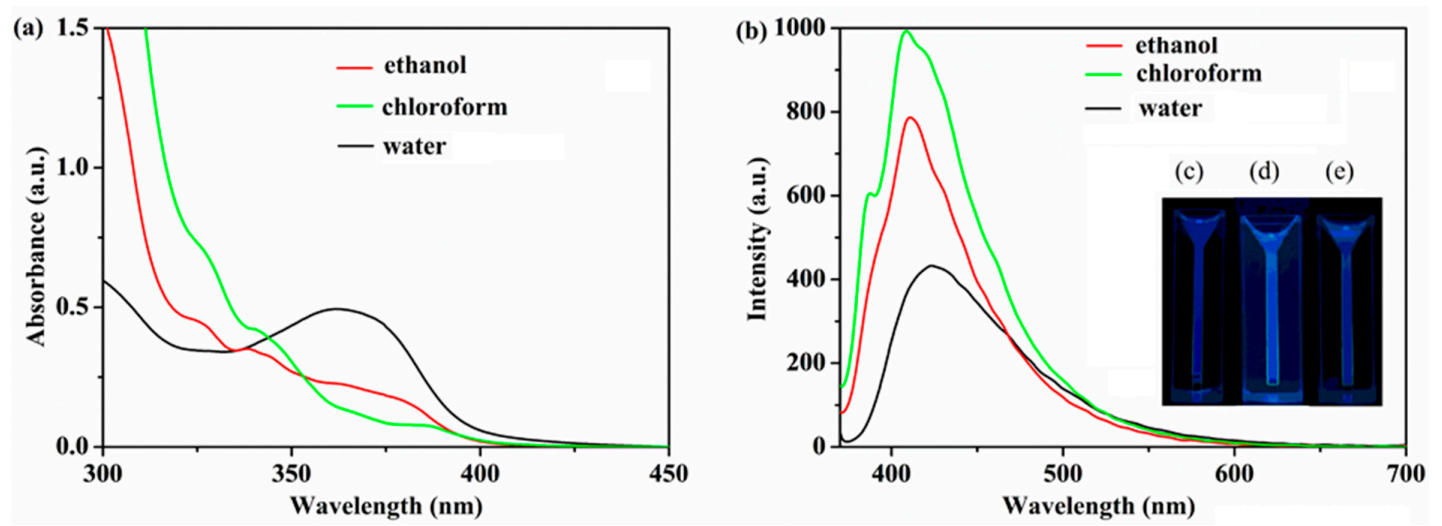

Figure 7. UV-Vis spectra (a) and PL spectra (b) of $\mathrm{ZnO}_{1: 2} / \mathrm{HPEI}-10$ nanocomposites which are dissolved in ethanol, chloroform and water, respectively. The inset (c-e) shows the photographs made under UV light of $\mathrm{ZnO}_{1: 2} / \mathrm{HPEI}-10$ nanocomposites which were dissolved in ethanol, chloroform and water, respectively.

HPEI, with a hyperbranched structure and many terminal amines, have been regarded as one of the most promising non-viral gene vectors. They are also widely used in uses, including gene transfection and drug delivery. While, $\mathrm{ZnO}$ QDs have excellent fluorescence and are non-toxic compared with cadmium-series QDs, the fluorescent $\mathrm{ZnO} / \mathrm{HPEI}$ nanocomposites combine the advantages of HPEI and $\mathrm{ZnO}$ QDs together, and have great prospects on bio-imaging, gene transfection, and drug release with $\mathrm{ZnO}$ QDs as fluorescence probes. Here, the application of $\mathrm{ZnO}_{1: 2} / \mathrm{HPEI}-10$ nanocomposites 
on bio-imaging was investigated. The COS-7 cells showed no fluorescence under a fluorescence microscope. However, after the COS-7 cells were cultured for $6 \mathrm{~h}$ in the PBS solution of $\mathrm{ZnO}_{1: 2} / \mathrm{HPEI}-10$ nanocomposites, it can be clearly seen that blue fluorescence was observed under a fluorescence microscope, as shown in Figure 8. This phenomenon indicates that the $\mathrm{ZnO}_{1: 2} / \mathrm{HPEI}-10$ nanocomposites could be internalized by COS-7 cells via endocytosis. Green et al. reported that bare cysteine-capped particles could not be endocytosed by the cells and cationic liposome treated QDs can be internalized into human breast cancer cells [39]. It can be seen that the transfection reagent is essential for cell imaging applications. Benefiting from the gene transfection property of $\mathrm{HPEI}$, the $\mathrm{ZnO}_{1: 2} / \mathrm{HPEI}-10$ nanocomposites could be easily endocytosed by cells.

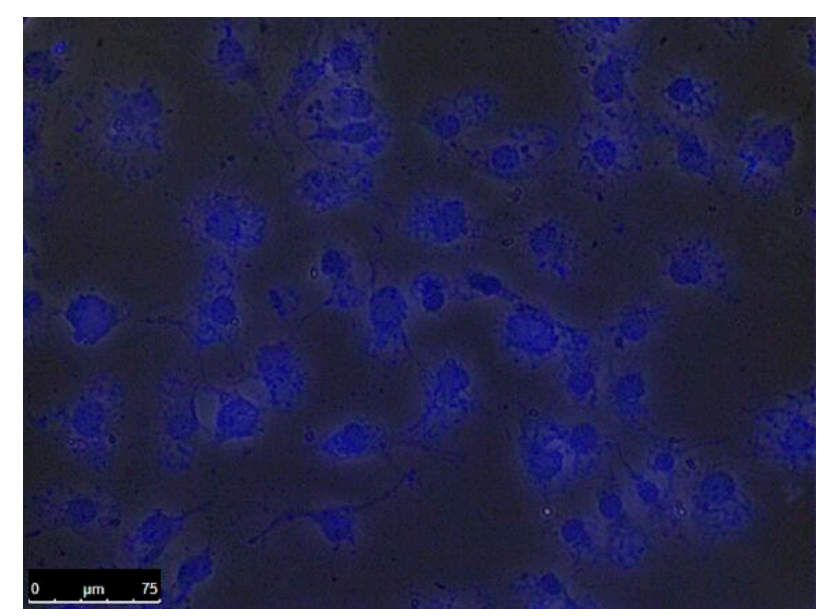

Figure 8. Fluorescence micrograph of COS-7 cells incubated with PBS solution of $\mathrm{ZnO}_{1: 2} / \mathrm{HPEI}-10$ nanocomposites.

\section{Conclusions}

In summary, water-soluble and oil-soluble HPEI were used as nanoreactors to synthesize uniform and amphibious $\mathrm{ZnO}$ QDs with blue fluorescence in ethanol. By changing $\left[\mathrm{Zn}^{2+}\right] /\left[\mathrm{OH}^{-}\right]$molar ratio and heating time, $\mathrm{ZnO}$ QDs with a QY of $30 \%$ were gained. The resulting $\mathrm{ZnO} / \mathrm{HPEI}$ nanocomposites in ethanol could be dissolved in chloroform and water after vacuum drying, or dialysis, respectively. The QY of $\mathrm{ZnO} / \mathrm{HPEI}$ nanocomposites can reach to $53 \%$ in chloroform and $11 \%$ in water. Thus, the application of the resulting $\mathrm{ZnO} / \mathrm{HPEI}$ nanocomposites could be extended, not only to optoelectronics, but also biomedical field (such as bio-imaging, gene transfection). The resulting water-soluble $\mathrm{ZnO} / \mathrm{HPEI}$ nanocomposites could easily be endocytosed by the COS-7 cells without transfection reagent and exhibited excellent biological imaging behavior.

Author Contributions: Conceptualization, Y.S.; methodology, G.L. and Y.S.; validation, G.L., L.Z., S.Y., R.C., and P.Z.; formal analysis, G.L., S.Y., R.C., and X.Z.; data curation, H.P., R.P., X.Z., Y.Y., Y.L., M.W., and Y.H.; writing-original draft preparation, G.L. and Y.S.; writing—review and editing, Y.S.; supervision, Y.S., J.D., W.D., and H.W. All authors have read and agreed to the published version of the manuscript.

Funding: This work is supported by the National Natural Science Foundation of China (21304001), the Joint Fund for Fostering Talents of National Natural Science Foundation of China and Henan province (U1204213), the Project of Science and Technology Development of Henan Province (192102310298) and the Plan for Scientific Innovation Talent of Henan Province (174200510017).

Conflicts of Interest: The authors declare no conflict of interest.

\section{References}

1. Smith, A.M.; Nie, S.M. Semiconductor nanocrystals: Structure, properties, and band gap engineering. Acc. Chem. Res. 2010, 43, 190-200. [CrossRef] [PubMed]

2. Regulacio, M.D.; Han, M.Y. Composition-tunable alloyed semiconductor nanocrystals. Acc. Chem. Res. 2010, 43, 621-630. [CrossRef] [PubMed] 
3. Zhao, N.N.; Yan, L.M.; Zhao, X.Y.; Chen, X.Y.; Li, A.H.; Zheng, D.; Zhou, X.; Dai, X.G.; Xu, F.J. Versatile types of organic/inorganic nanohybrids: From strategic design to biomedical applications. Chem. Rev. 2019, 119, 1666-1762. [CrossRef] [PubMed]

4. Jalali, H.B.; Sadeghi, S.; Sahin, M.; Ozturk, H.; Ow-Yang, C.W.; Nizamoglu, S. Colloidal aluminum antimonide quantum dots. Chem. Mater. 2019, 31, 4743-4747. [CrossRef]

5. Lu, H.P.; Carroll, G.M.; Neale, N.R.; Beard, M.C. Infrared quantum dots: Progress, challenges, and opportunities. ACS Nano 2019, 13, 939-953. [CrossRef]

6. Li, M.X.; Chen, T.; Gooding, J.J.; Liu, J.Q. Review of carbon and graphene quantum dots for sensing. ACS Sens. 2019, 4, 1732-1748. [CrossRef]

7. Bhandari, S.; Hao, B.; Waters, K.; Lee, C.H.; Idrobo, J.C. Two-dimensional gold quantum dots with tunable bandgaps. ACS Nano 2019, 13, 4347-4353. [CrossRef]

8. Gao, M.; Lesser, C.; Kirstein, S.; Möhwald, H.; Rogach, A.L.; Weller, H. Electroluminescence of different colors from polycation/CdTe nanocrystal self-assembled films. J. Appl. Phys. 2000, 87, 2297-2302. [CrossRef]

9. Carey, G.H.; Abdelhady, A.L.; Ning, Z.J.; Thon, S.M.; Bakr, O.M.; Sargent, E.H. Colloidal quantum dot solar cells. Chem. Rev. 2015, 115, 12732-12763. [CrossRef]

10. Chan, W.C.W.; Nie, S. Quantum dot bioconjugates for ultrasensitive nonisotopic detection. Science 1998, 281, 2016-2018. [CrossRef]

11. Bruchez, M.; Moronne, M.; Gin, P.; Weiss, S.; Alivisatos, A.P. Semiconductor nanocrystals as fluorescent biological labels. Science 1998, 281, 2013-2015. [CrossRef] [PubMed]

12. Pisanic, T.R., II; Zhang, Y.; Wang, T.H. Quantum dots in diagnostics and detection: Principles and paradigms. Analyst 2014, 139, 2968-2981. [CrossRef] [PubMed]

13. Wegner, K.D.; Hildebrandt, N. Quantum dots: Bright and versatile in vitro and in vivo fluorescence imaging biosensors. Chem. Soc. Rev. 2015, 44, 4792-4834. [CrossRef] [PubMed]

14. Xu, G.X.; Zeng, S.W.; Zhang, B.T.; Swihart, M.T.; Yong, K.T.; Prasad, P.N. New generation cadmium-free quantum dots for biophotonics and nanomedicine. Chem. Rev. 2016, 116, 12234-12327. [CrossRef]

15. Chen, G.Y.; Roy, I.; Yang, C.H.; Prasad, P.N. Nanochemistry and nanomedicine for nanoparticle-based diagnostics and therapy. Chem. Rev. 2016, 116, 2826-2885. [CrossRef]

16. Farokhzad, O.C.; Langer, R. Nanomedicine: Developing smarter therapeutic and diagnostic modalities. Adv. Drug Deliv. Rev. 2006, 58, 1456-1459. [CrossRef]

17. Chen, O.; Chen, X.; Yang, Y.G.; Lynch, J.; Wu, H.M.; Zhuang, J.Q.; Cao, Y.C. Synthesis of metal-selenide nanocrystals using selenium dioxide as the selenium porecursor. Angew. Chem. Int. Ed. 2008, 47, 8638-8641. [CrossRef]

18. Chen, O.; Zhao, J.; Chauhan, V.P.; Cui, J.; Wong, C.; Harris, D.K.; Wei, H.; Han, H.S.; Fukumura, D.; Jain, R.K.; et al. Compact high-quality CdSe-CdS core-shell nanocrystals with narrow emission linewidths and suppressed blinking. Nat. Mater. 2013, 12, 445-451. [CrossRef]

19. Pradhan, N.; Battaglia, D.M.; Liu, Y.C.; Peng, X.G. Efficient, stable, small, and water-soluble doped ZnSe nanocrystal emitters as non-cadmium biomedical labels. Nano Lett. 2007, 7, 312-317. [CrossRef]

20. Fu, Y.S.; Du, X.W.; Kulinich, S.A.; Qiu, J.S.; Qin, W.J.; Li, R.; Sun, J.; Liu, J. Stable aqueous dispersion of ZnO quantum dots with strong blue emission via simple solution route. J. Am. Chem. Soc. 2007, 129, 16029-16033. [CrossRef]

21. Wang, Y.F.; He, L.; Yu, B.; Chen, Y.; Shen, Y.Q.; Cong, H.L. ZnO quantum dots modified by pH-activated charge-reversal polymer for tumor targeted drug delivery. Polymers 2018, 10, 1272. [CrossRef] [PubMed]

22. Lee, D.; Wolska-Pietkiewicz, M.; Badoni, S.; Grala, A.; Lewiński, J.; Paëpe, G.D. Disclosing interfaces of ZnO nanocrystals using dynamic nuclear polarization sol-gel versus organometallic approach. Angew. Chem. 2019, 131, 17323-17328. [CrossRef]

23. Derfus, A.M.; Chan, W.C.W.; Bhatia, S.N. Probing the cytotoxicity of semiconductor quantum dots. Nano Lett. 2004, 4, 11-18. [CrossRef] [PubMed]

24. Asok, A.; Gandhi, M.N.; Kulkarni, A.R. Enhanced visible photoluminescence in ZnO quantum dots by promotion of oxygen vacancy formation. Nanoscale 2012, 4, 4943-4946. [CrossRef] [PubMed]

25. Cao, H.L.; Qian, X.F.; Gong, Q.; Du, W.M.; Ma, X.D.; Zhu, Z.K. Shape- and size-controlled synthesis of nanometre $\mathrm{ZnO}$ from a simple solution route at room temperature. Nanotechnology 2006, 17, 3632-3636. [CrossRef] 
26. Hu, Y.; Mei, T.; Guo, J.; White, T. Temperature-triggered self-assembly of ZnO: From nanocrystals to nanorods to tablets. Inorg. Chem. 2007, 46, 11031-11035. [CrossRef]

27. Liu, D.P.; Li, G.D.; Su, Y.; Chen, J.S. Highly luminescent ZnO nanocrystals stabilized by ionic-liquid components. Angew. Chem. Int. Ed. 2006, 45, 7370-7373. [CrossRef]

28. Xiong, H.M.; Liu, D.P.; Xia, Y.Y.; Chen, J. Polyether-grafted ZnO nanoparticles with tunable and stable photoluminescence at room temperature. Chem. Mater. 2005, 17, 3062-3064. [CrossRef]

29. Xiong, H.M.; Wang, Z.D.; Liu, D.P.; Chen, J.S.; Wang, Y.G.; Xia, Y.Y. Bonding polyether onto ZnO nanoparticles: An effective method for preparing polymer nanocomposites with tunable luminescence and stable conductivity. Adv. Funct. Mater. 2005, 15, 1751-1756. [CrossRef]

30. Saliba, S.; Serrano, C.V.; Keilitz, J.; Kahn, M.L.; Mingotaud, C.; Haag, R.; Marty, J.D. Hyperbranched polymers for the formation and stabilization of $\mathrm{ZnO}$ nanoparticles. Chem. Mater. 2010, 22, 6301-6309. [CrossRef]

31. Xiong, H.M.; Xu, Y.; Ren, Q.G.; Xia, Y.Y. Stable aqueous ZnO@polymer core-shell nanoparticles with tunable photoluminescence and their application in cell imaging. J. Am. Chem. Soc. 2008, 130, 7522-7523. [CrossRef] [PubMed]

32. Xiong, H.M.; Wang, Z.D.; Xia, Y.Y. Polymerization initiated by inherent free radicals on nanoparticle surfaces: A simple method of obtaining ultrastable ZnO@polymer core-shell nanoparticles with strong blue fluorescence. Adv. Mater. 2006, 18, 748-751. [CrossRef]

33. Zhang, Z.Y.; Xu, Y.D.; Ma, Y.Y.; Qiu, L.L.; Wang, Y.; Kong, J.L.; Xiong, H.M. Biodegradable ZnO@polymer core-shell nanocarriers: pH-triggered release of doxorubicin in vitro. Angew. Chem. 2013, 125, 4221-4225. [CrossRef]

34. Boussif, O.; Lezoualc’h, F.; Zanta, M.A.; Mergny, M.D.; Scherman, D.; Demeneix, B.; Behr, J.P. A versatile vector for gene and oligonucleotide transfer into cells in culture and in vivo: Polyethylenimine. Proc. Natl. Acad. Sci. USA 1995, 92, 7297-7301. [CrossRef] [PubMed]

35. Chen, G.H.; Chen, W.J.; Wu, Z.; Yuan, R.X.; Li, H.; Gao, J.M.; Shuai, X.T. MRI-visible polymeric vector bearing $\mathrm{CD}_{3}$ single chain antibody for gene delivery to $\mathrm{T}$ cells for immunosuppression. Biomaterials 2009, 30, 1962-1970. [CrossRef]

36. Shi, Y.F.; Zhou, L.Z.; Wang, R.B.; Pang, Y.; Xiao, W.C.; Li, H.Q.; Su, Y.; Wang, X.L.; Zhu, B.S.; Zhu, X.Y.; et al. In situ preparation of magnetic nonviral gene vectors and magnetofection in vitro. Nanotechnology 2010, 21, 115103. [CrossRef]

37. Shi, Y.F.; Du, J.M.; Zhou, L.Z.; Li, X.T.; Zhou, Y.H.; Li, L.L.; Zang, X.X.; Zhang, X.Y.; Pan, F.C.; Zhang, H.H.; et al. Size-controlled preparation of magnetic iron oxidenanocrystals within hyperbranched polymers and their magnetofection in vitro. J. Mater. Chem. 2012, 22, 355-360. [CrossRef]

38. Crosby, G.A.; Demas, J.N. Measurement of photoluminescence quantum yields. J. Phys. Chem. 1971, 75, 991-1024. [CrossRef]

39. Green, M.; Harwood, H.; Barrowman, C.; Rahman, P.; Eggeman, A.; Festry, F.; Dobsonb, P.; Ng, T. A facile route to CdTe nanoparticles and their use in bio-labelling. J. Mater. Chem. 2007, 17, 1989-1994. [CrossRef] 